\title{
Distribution, habitat preferences and behaviour of the critically endangered Maltese top-shell Gibbula nivosa (Gastropoda: Trochidae)
}

\author{
Julian Evans $\cdot$ Joseph A. Borg $\cdot$ Patrick J. Schembri
}

Received: 23 July 2010/ Accepted: 8 November 2010/Published online: 23 November 2010

(C) Springer-Verlag 2010

\begin{abstract}
The Maltese top-shell, Gibbula nivosa Adams 1851 , is a critically endangered marine trochid gastropod endemic to the Maltese Islands (central Mediterranean). Previously unrecorded live since 1981, rediscovery of this species in 2006 has enabled the collection of basic biological data for the first time, based on a population in Sliema Creek. The field distribution and habitat preferences of G. nivosa were investigated via stratified random sampling, while aspects of its behaviour were studied through laboratory experiments. Gibbula nivosa occurred primarily in near-homogeneous or homogeneous infralittoral cobble/pebble beds, at an overall density of $17.6 \pm 25.0 \mathrm{SD}$ individuals $\mathrm{m}^{-2}$; however, large spatial and temporal variations in abundance were recorded. The snails did not exhibit gregarious behaviour and the slightly clumped dispersion pattern noted in the field appeared to result from patchiness of the habitat. Recruitment was observed in post-summer months, which, together with data on shell-size distributions, suggests that G. nivosa spawns in early summer and attains adult size (maximum shell width $\sim 9 \mathrm{~mm}$ ) in less than 1 year. Gibbula nivosa showed a circadian activity pattern with nocturnal foraging involving indiscriminate ingestion of particles browsed off the substratum; observations on responses to four potential predators suggest that nocturnal activity may have evolved in response to diurnal predation. Historical records of snail occurrence and the present study suggest that population
\end{abstract}

Communicated by U. Sommer.

J. Evans $(\bowtie)$ - J. A. Borg · P. J. Schembri

Department of Biology, University of Malta,

Msida MSD2080, Malta

e-mail: sur.evans@gmail.com declines of $G$. nivosa in the past were probably related to habitat alteration as a result of anthropogenic pressure.

\section{Introduction}

The Maltese top-shell, Gibbula nivosa, is a critically endangered marine trochid gastropod (Schembri et al. 2007; Evans et al. 2010). First described by Adams (1851), it has since been recorded from the Maltese Islands on numerous occasions (Kobelt 1888; Despott 1919; Caruana Gatto and Despott 1919; Ghisotti 1976; Palazzi 1978; Cachia 1981; Evans et al. 2010), but not from any other locality in the Mediterranean, despite extensive searches for this species by shell collectors (Schembri 1985). Gibbula nivosa is thus considered to be endemic to the Maltese Islands (Ghisotti 1976; Giannuzzi-Savelli et al. 1997) and is a rare case of marine point endemism. Such a situation is practically unique amongst molluscs within the whole Mediterranean region (Palazzi 1978) as well as amongst the marine invertebrates of Malta; although a handful of other marine species are also known only from the Maltese Islands, none of these have been extensively searched for throughout the Mediterranean, as in the case of G. nivosa.

Given the small size of the Maltese Islands-the archipelago has a collective area of only $315 \mathrm{~km}^{2}$ and a combined coastline of just $271 \mathrm{~km}$ (Mallia et al. 2002) $G$. nivosa has a very narrow geographical range, which makes this species very rare on a regional scale, and vulnerable to extinction (Boudouresque 2004). However, G. nivosa is also rare within the Maltese Islands themselves. For instance, Palazzi (1978) searched 13 different locations specifically for G. nivosa but found live individuals in only one site (St. Thomas Bay). Cachia (1981) noted live individuals at Santa Marija Bay and Delimara 
Point in addition to St. Thomas Bay, but there were no further records of live G. nivosa in $>25$ years (between 1981 and 2006), despite more recent intensive searches for this species at these localities (Schembri et al. 2007).

Given its rarity, indiscriminate collection of $G$. nivosa threatens it with extinction, especially since collectors prefer fresh shells that are best obtained by collecting live individuals. In fact, Scotti and Chemello (2000) consider G. nivosa to be the species at the greatest risk of extinction amongst the Mediterranean marine malacofauna. Despite calls for biologists and shell collectors to refrain from collecting this species (Palazzi 1978), G. nivosa started to appear in the catalogues of professional shell dealers (Schembri 1985; Thake and Schembri 1989) and was subsequently afforded protection via international conventions: the Bern Convention on the conservation of European wildlife and natural habitats, the Protocol concerning specially protected areas and biological diversity in the Mediterranean of the Barcelona Convention, and the European Union's 'Habitats Directive' (Council Directive 93/43/EEC on the conservation of natural habitats and of wild flora and fauna); the species is also protected by Maltese legislation (Flora, fauna and natural habitats protection regulations, 2006).

By rendering the collection and trade of G. nivosa illegal, such legislation has contributed to ensuring survival of this species. However, while knowledge of the biology of this species is required for proper conservation management, no such information is available since early workers on the species were primarily interested in taxonomy, and live individuals of $G$. nivosa were not available after 1981. Consequently, all that is known about G. nivosa is scanty information on its distribution, shell morphology and radular structure, with the ecology and behaviour of this species virtually unknown. Such information cannot be inferred from other Gibbula spp. that are closely related to $G$. nivosa (i.e. those classified within the sub-genus Colliculus) because none of these species has been studied in detail. Following the discovery in 2006 of a living population of G. nivosa in Marsamxett Harbour (see Evans et al. 2010), studies were undertaken to obtain basic information on the ecology and behaviour of this species, as reported here. Our data, which are the first of their kind for G. nivosa, will be very useful for the conservation management of the species.

\section{Materials and methods}

Field surveys

Preliminary surveys indicated the presence of living populations of Gibbula nivosa at two localities in the Maltese
Islands: off western Comino and in Sliema Creek within Marsamxett Harbour (Fig. 1), with the largest population occurring at the latter locality. The habitat of the species at Sliema Creek consists of a gently sloping bottom of gravelly sand and silt with overlying cobbles and pebbles within the 5-12 m depth range (Evans et al. 2010). A pilot study at this locality in November 2007 showed patchiness in the cobble/pebble habitat, which was therefore classified into three different substratum categories: (1) non-homogeneous cobble/pebble bed, with cobbles and pebbles intermixed with small boulders; (2) near-homogeneous cobble/pebble bed, covering $40-80 \%$ in an area of at least $2 \mathrm{~m}^{2}$; and (3) homogeneous cobble/pebble bed, covering $80-100 \%$ in an area of at least $2 \mathrm{~m}^{2}$. Detailed mapping of these habitats was carried out using a series of shore-normal transects that were $10 \mathrm{~m}$ apart, following the procedure of Borg et al. (1997).

To collect data on population abundance, stratified random sampling was carried out at nine stations (T1-T6 at Tigné, M1-M3 at Manoel Island; Fig. 1) during a 4-week period from mid-December 2007 to mid-January 2008. Three samples were collected from each substratum category present at each station using a $0.1-\mathrm{m}^{2}$ circular sampler (see Borg et al. 2002). Since the cobble beds were stratified (Evans et al. 2010), the top layer of cobbles and pebbles was carefully hand-picked and transferred to a $0.5-\mathrm{mm}$ mesh bag, while a small fine-mesh hand net was used to scoop the basal layer of finer granules (particles $>1 \mathrm{~mm}$ ) into a separate mesh bag. This ensured the collection of any shells $>1 \mathrm{~mm}$ that were present on the cobbles and pebbles or within the lower layer of granules. Following removal of the cobble/pebble stratum, its thickness was measured in situ using a $30-\mathrm{cm}$ ruler.

Samples were sorted in the laboratory, all molluscs present were identified, and live individuals of G. nivosa were counted to obtain a measure of the population density in each layer (upper layer of cobbles/pebbles and basal layer of granules) of each of the different substratum categories present at each station. Following sample processing, all individuals of G. nivosa were returned to the original site of collection. The population density in the homogenous cobble/pebble bed at Station T3 (the station with the highest abundance) was re-estimated in November 2008 using three $1-\mathrm{m}^{2}$ quadrats. Each quadrat was subdivided into a $3 \times 3$ grid, and the number of $G$. nivosa individuals in each of the nine $0.11-\mathrm{m}^{2}$ sub-quadrats was counted in situ, taking care to place the cobbles and pebbles back so as to minimise disturbance. Since counting was carried out in situ, the duration of each of these sampling sessions was recorded so as to estimate the catch per unit effort.

To obtain information on the habitat and microhabitat preferences of G. nivosa, differences in population density 
Fig. 1 a Map of Maltese Islands showing sites where live individuals of Gibbula nivosa have been recorded (dates in parentheses), with two sites where live G. nivosa were found in the present study indicated in bold, $\mathbf{b}$ benthic habitats map of Sliema Creek (site 4) showing nine sampling stations, T1-T6 and $\mathrm{M} 1-\mathrm{M} 3$

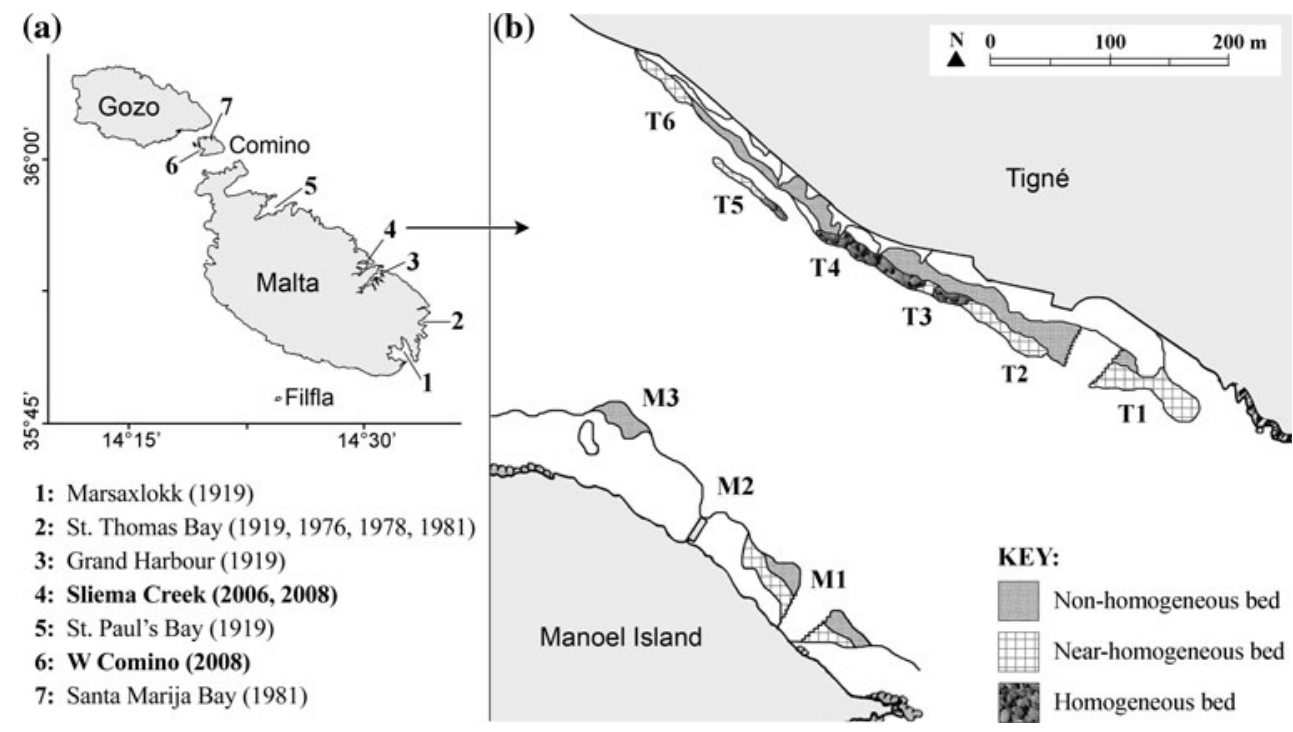

between different stations, cobble/pebble bed categories, substratum vertical layers and sites having different cobble thicknesses were tested using the Kruskal-Wallis test or the Mann-Whitney $U$ test, as appropriate. Parametric tests could not be used since the data did not meet the assumption of normality. The population density data together with estimates of the cover area for each substratum category were used to estimate the total population size of G. nivosa within Sliema Creek. Quadrat sampling enabled the collection of data on the dispersion pattern of the gastropod in the field. This was studied by calculating Green's Index (Green 1966) for the whole habitat, separately for each substratum category, and also for the homogenous cobble/pebble bed at Station T3 using the counts obtained from the $3 \times 3$ gridded quadrats.

\section{Laboratory experiments}

Individuals of $G$. nivosa used in laboratory experiments were collected from the homogeneous cobble/pebble bed at Station T3 (Fig. 1). Fresh specimens were collected from the field through standard search techniques before the start of each experiment; these were kept in well-aerated seawater aquaria containing a replica of the cobble/pebble substratum. The snails were subsequently returned to the original site of collection upon completion of the experiment. The duration of each sampling session was recorded so as to obtain a measure of the catch per unit effort. Sampling was conducted in March and May 2008.

The activity patterns of $G$. nivosa were investigated in March 2008, when a photoperiod of 9-h light:15-h dark prevailed. Eight 'Perspex' aquaria $(35 \mathrm{~cm} \times 20 \mathrm{~cm} \times$ $25 \mathrm{~cm}$ ) were set up with a cobble/pebble substratum and eight snails (shell widths: $6.0-7.5 \mathrm{~mm}$ ), whose shells were marked with lacquer for easy spotting at night, were introduced into each aquarium. After an initial 24-h acclimatisation period, the number of individuals actively moving or feeding was counted at 4-h intervals; snails that remained buried in the cobble layer were deemed to be inactive. Light intensity was recorded using a luminance meter (LI-COR LI-250 fitted with LI-193SA spherical quantum sensor), taking care that the maximum intensity was comparable to that measured in the field (photon flux density of $\sim 600 \mu \mathrm{mol} \mathrm{s}^{-1} \mathrm{~m}^{-2}$ ). A 'runs test' was performed to check for serial randomness in the data using the median as cut-off point (e.g. Zar 1996). Autocorrelation and cross-correlation (with light intensity) time-series analyses were carried out to obtain correlograms as described by Chatfield (2004) and thus determine the time period of any activity cycles present.

A similar laboratory setup was used to test for gregarious behaviour but in this case the shells of the eight snails in each aquarium were marked with different colours so that the position of each individual could be recorded. During this experiment, which was also carried out in March 2008, measurements were taken daily at 20:00 hours (the time when most snails were visible at the surface of the cobbles, see below in 'Results') for 7 days. Nearest-neighbour analysis was then carried out by computing the ' $R$ ' statistic for each replicate and testing for significant departures in the $R$ value from that expected under a random distribution, as described by Clark and Evans (1954).

In the absence of cobbles, individuals of $G$. nivosa were noted grazing along the sides of aquaria when they became active. This was used to make observations on their foraging behaviour by obtaining traces of the snails' movements as they crawled over the aquarium walls. Observations were made in May 2008 using adult snails (shell widths $6.5-8.0 \mathrm{~mm}$ ) and 48 traces were obtained in 
all, each from a separate individual. The ratio between the actual distance $(s)$ moved by each snail and its linear displacement $(d)$ from start to finish was used as a 'coverage index' $(s / d)$, indicating the degree of side-to-side motion as the molluscs grazed over the aquarium walls. The duration $(t)$ of each observation was also noted so as to estimate the speed at which the snails were moving while grazing, computed from the distance travelled during that time interval (i.e. $s / t$ ).

Faecal content analysis was used to study the diet of G. nivosa; direct observations in the field were ruled out since the species exhibited nocturnal activity (see below in 'Results') and could not be observed without being disturbed, while stomach content analysis was avoided since this would necessitate killing individuals. For faecal content analysis, 20 adult individuals were placed in separate vessels containing filtered sea water immediately upon collection (in May 2008) and left undisturbed for 3-4 h, during which time defecation occurred. Ten pellets from each vessel were mounted on separate microscope slides and macerated by gentle grinding with the coverslips. The faecal content of each group of pellets was then assessed by observation under a stereomicroscope, expressing the faecal composition in terms of the relative abundance of each of five categories of material: (1) mineral particles, (2) organic detritus, (3) macrophyte remains, (4) diatoms and Foraminifera and (5) remains of macroscopic invertebrates.

The response of $G$. nivosa to the presence of potential predators was also investigated in May 2008. For each experiment, ten aquaria were set up and a single individual was introduced in each and left for $1 \mathrm{~h}$ to acclimatise. The experiments were carried out while the snails were active. Three separate experiments were carried out to note the snails' reactions to: (1) turbulence of the aquarium water (produced by stirring), (2) abrupt changes in light intensity (i.e. shadow casting) and (3) shell tapping, measuring the time taken by the individuals to re-emerge from their shells in each case. In subsequent experiments, the individual snails were each exposed to one of four sympatric species that could potentially be predators of $G$. nivosa, namely a crab (Xantho poressa), starfish (Echinaster sepositus), cephalopod (Octopus vulgaris) and fish (Symphodus mediterraneus), classifying the gastropods' reactions as 'evasive' or 'non-evasive'. Each experiment was repeated twice (thus using a total of 20 individuals). A Student's $t$-test was used to determine whether the number of individuals taking evasive measures was significantly different from those reacting in a non-evasive manner.

Finally, the shell width of all individuals collected during March 2008 and November 2008 was measured using a stereomicroscope fitted with an eye-piece graticule having an accuracy of $\pm 0.05 \mathrm{~mm}$. These measurements, together with similar data collected in September 2006 when live G. nivosa were first discovered, were coupled with estimates of population density recorded at the same time to indicate the population size structure and dynamics of G. nivosa in Sliema Creek.

\section{Results}

Population attributes

The population density of Gibbula nivosa differed significantly among stations (Kruskal-Wallis test, $H_{7}=17.271$, $P=0.016)$ and among different substratum categories (Kruskal-Wallis test, $H_{2}=6.739, P=0.034$ ). In the latter case, the abundance of snails was lower in the nonhomogeneous cobble/pebble habitat compared to nearhomogeneous and homogeneous cobble/pebble habitats (Table 1). The overall mean population density, calculated across all quadrats, was $17.6 \pm 25.0 \mathrm{SD}$ individuals $\mathrm{m}^{-2}$ $(\mathrm{CV}=142 \%)$. A significantly higher abundance was recorded from the upper cobble stratum compared to the basal layer of finer sediment (Mann-Whitney $U$ test, $\left.U=1,173, n_{1}=n_{2}=54, P=0.018\right)$ but no such differences were observed among samples collected from sites having different thickness of the cobble/pebble stratum (Mann-Whitney $U$ test, $U=186, n_{1}=45, n_{2}=9$, $P=0.642$ ).

Large temporal variation in the population density of G. nivosa was evident (Table 2). The highest values were recorded in autumn (September and November). Abundances were lower in subsequent sampling sessions, with the lowest catch per unit effort recorded between March and May 2008. Based on the abundance values recorded between December 2007 and January 2008, and values of cover of the different substratum categories (Fig. 1), the total population size of G. nivosa in Sliema Creek was estimated at $\sim 100,000$ individuals (Table 1 ). However, the large spatial and temporal variation in population density suggests that although $G$. nivosa appeared to be abundant in Sliema Creek, its population size is very variable and at certain times of the year this may be much lower than the estimated value.

Preliminary data on the population size structure of G. nivosa (Fig. 2) at three different times of the year show a unimodal distribution of shell sizes at all times, with the difference in shell width of the largest and smallest snails never exceeding $3 \mathrm{~mm}$. Mean shell width of individuals collected in November 2008 was slightly larger than that recorded in September 2006, while considerably larger snails were collected in March 2008 (Table 2). However, live individuals having a shell width $>6 \mathrm{~mm}$ were no longer present in November 2008. 
Table 1 Mean population density of individuals of Gibbula nivosa collected in December 2007/January 2008, area covered by each cobble/ pebble bed category, abundance estimates per station and an estimate of total population size

\begin{tabular}{|c|c|c|c|c|c|c|c|c|c|c|c|}
\hline \multirow[t]{2}{*}{ Station } & \multicolumn{3}{|c|}{ Mean population density $( \pm \mathrm{SD})$ (individuals $\mathrm{m}^{-2}$ ) } & \multicolumn{4}{|c|}{ Coverage area $\left(\mathrm{m}^{2}\right)$} & \multicolumn{4}{|c|}{ Estimated population size (individuals) } \\
\hline & A & $\mathrm{B}$ & $\mathrm{C}$ & A & $\mathrm{B}$ & $\mathrm{C}$ & Total & A & B & $\mathrm{C}$ & Total \\
\hline $\mathrm{T} 1$ & $\mathrm{n} / \mathrm{a}$ & $23.3 \pm 40.4$ & $\mathrm{n} / \mathrm{a}$ & $\mathrm{n} / \mathrm{a}$ & 700 & $\mathrm{n} / \mathrm{a}$ & 700 & $\mathrm{n} / \mathrm{a}$ & 16,310 & $\mathrm{n} / \mathrm{a}$ & 16,310 \\
\hline $\mathrm{T} 2$ & $13.3 \pm 15.3$ & $60 \pm 20$ & $\mathrm{n} / \mathrm{a}$ & 200 & 500 & $\mathrm{n} / \mathrm{a}$ & 700 & 2,660 & 30,000 & $\mathrm{n} / \mathrm{a}$ & 32,660 \\
\hline T3 & 0 & $13.3 \pm 23.1$ & $43.3 \pm 23.1$ & 1,000 & 400 & 500 & 1,900 & 0 & 5,320 & 21,650 & 26,970 \\
\hline T4 & 0 & 0 & $3.3 \pm 5.8$ & 700 & 200 & 500 & 1,400 & 0 & 0 & 1,650 & 1,650 \\
\hline T5 & $3.3 \pm 5.8$ & $16.7 \pm 20.8$ & $3.3 \pm 5.8$ & 600 & 300 & 200 & 1,100 & 1,980 & 5,010 & 660 & 7,650 \\
\hline T6 & 0 & 0 & $\mathrm{n} / \mathrm{a}$ & 200 & 600 & $\mathrm{n} / \mathrm{a}$ & 800 & 0 & 0 & $\mathrm{n} / \mathrm{a}$ & 0 \\
\hline M1 & 0 & 0 & $\mathrm{n} / \mathrm{a}$ & 400 & 200 & $\mathrm{n} / \mathrm{a}$ & 600 & 0 & 0 & $\mathrm{n} / \mathrm{a}$ & 0 \\
\hline M2 & $\mathrm{n} / \mathrm{a}$ & $\mathrm{n} / \mathrm{a}$ & $\mathrm{n} / \mathrm{a}$ & $\mathrm{n} / \mathrm{a}$ & $\mathrm{n} / \mathrm{a}$ & $\mathrm{n} / \mathrm{a}$ & $\mathrm{n} / \mathrm{a}$ & $\mathrm{n} / \mathrm{a}$ & $\mathrm{n} / \mathrm{a}$ & $\mathrm{n} / \mathrm{a}$ & $\mathrm{n} / \mathrm{a}$ \\
\hline \multirow[t]{2}{*}{ M3 } & 0 & $30 \pm 20$ & $\mathrm{n} / \mathrm{a}$ & 200 & 400 & $\mathrm{n} / \mathrm{a}$ & 600 & 0 & 12,000 & $\mathrm{n} / \mathrm{a}$ & 12,000 \\
\hline & & & Total & 3,300 & 3,300 & 1,200 & 7,800 & 4,640 & 68,640 & 23,960 & 97,240 \\
\hline
\end{tabular}

$A$ Non-homogeneous cobble/pebble bed; $B$ near-homogeneous cobble/pebble bed; $C$ homogeneous cobble/pebble bed; $n / a$ no cobble/pebble bed present

Table 2 Variation in population density recorded at Station T3 in terms of individuals $\mathrm{m}^{-2}$ estimated from quadrat counts and individuals $\mathrm{h}^{-1}$ estimated from catch per unit effort during standard searches, together with mean shell width of individuals

\begin{tabular}{|c|c|c|c|}
\hline $\begin{array}{l}\text { Sampling } \\
\text { date }\end{array}$ & $\begin{array}{l}\text { Mean density } \\
( \pm \mathrm{SD}) \\
\text { (individuals } \mathrm{m}^{-2} \text { ) }\end{array}$ & $\begin{array}{l}\text { Catch per unit } \\
\text { effort }( \pm \mathrm{SD}) \\
\text { (individuals } \mathrm{h}^{-1} \text { ) }\end{array}$ & $\begin{array}{l}\text { Mean shell } \\
\text { width } \\
( \pm \mathrm{SD}) \\
(\mathrm{mm})\end{array}$ \\
\hline Sept 2006 & $163.3 \pm 179.3$ & $\mathrm{n} / \mathrm{a}$ & $3.82 \pm 0.44$ \\
\hline $\begin{array}{l}\text { Dec } 2007 / \mathrm{Jan} \\
2008\end{array}$ & $43.3 \pm 23.1$ & $\mathrm{n} / \mathrm{a}$ & $\mathrm{n} / \mathrm{a}$ \\
\hline March 2008 & $\mathrm{n} / \mathrm{a}$ & 20.7 & $6.78 \pm 0.43$ \\
\hline May 2008 & $\mathrm{n} / \mathrm{a}$ & $3.9 \pm 2.0$ & $\mathrm{n} / \mathrm{a}$ \\
\hline Nov 2008 & $174.3 \pm 129.7$ & $50.2 \pm 33.0$ & $4.38 \pm 0.44$ \\
\hline
\end{tabular}

$n / a$ Not available

\section{Behaviour}

The activity patterns of G. nivosa are summarised in Fig. 3 . A significantly non-random pattern was observed (Runs test, $Z=-2.494, P=0.013$ ), which was shown by the autocorrelation analysis to have a $24-h$ periodicity. Snail activity was negatively correlated with light intensity; maximum activity was recorded at the onset of complete darkness. Thus, G. nivosa exhibited a circadian rhythm with nocturnal activity. While active, G. nivosa foraged on the surface of the cobbles. Only slight differences were noted between the faecal content of different individuals; this invariably consisted of $45-55 \%$ mineral particles and 38-48\% organic detritus, with other material making up $<10 \%$ of the faeces in all cases. Foraging traces revealed that the snails did not intensively graze a given area, but browsed the substratum as they crawled forward at an average velocity of $20.4 \pm$ $0.9 \mathrm{SD} \mathrm{mm} \mathrm{min}^{-1}$, while simultaneously shifting the buccal
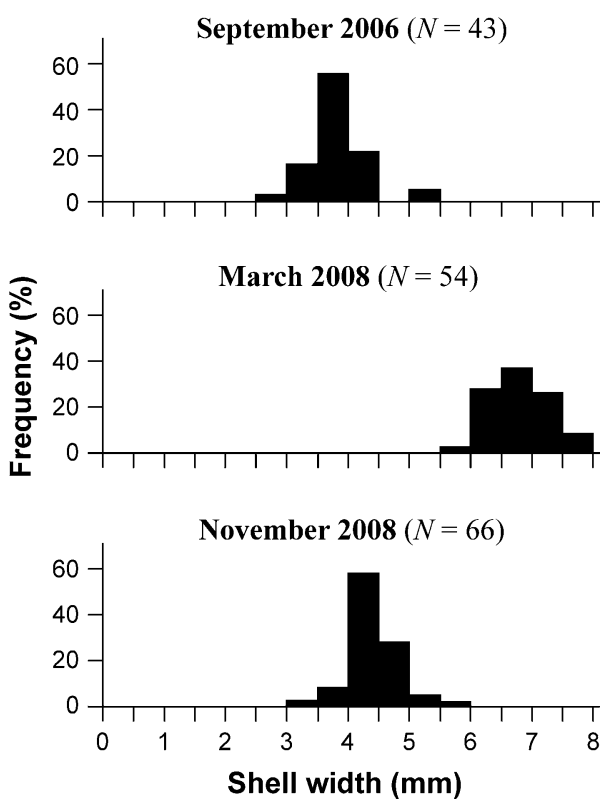

Fig. 2 Size frequency histograms showing population size structure of Gibbula nivosa in September 2006, March 2008 and November 2008

region from side to side to increase the area of substratum scoured for food (mean coverage index $=1.42 \pm 0.38 \mathrm{SD}$ ); this is known as "pendulum motion" (Ankel 1938).

In the predator defence experiments, G. nivosa did not react to agitation of the aquarium water and continued to forage. Casting a shadow resulted in the individuals partially withdrawing into their shells while leaving the eyes and cephalic tentacles exposed; however, the snails resumed foraging within a few seconds. Shell tapping, on the other hand, resulted in immediate complete withdrawal, which lasted for a mean duration of $16.90 \pm 5.36 \mathrm{SD}$ s, after which the snails lifted the shell slightly and 


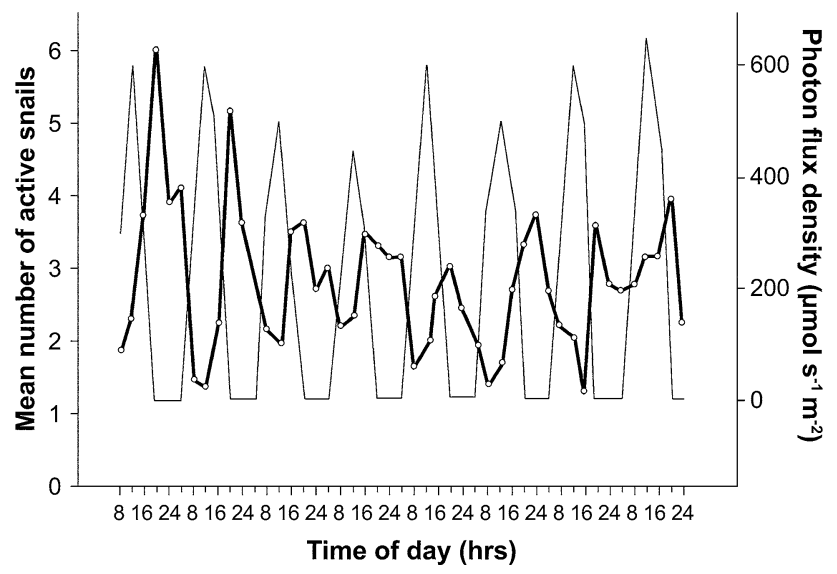

Fig. 3 Variation in mean number of active individuals of Gibbula nivosa per aquarium (thick line) and light intensity (thin line) with time of day for eight successive days $(N=8$ per aquarium)

extended their cephalic tentacles for a few seconds before re-emerging from the shell. The presence of a crab, $X$. poressa, and of a starfish, E. sepositus, elicited no response from G. nivosa, while only $30 \%$ of the individuals tested showed some form of evasive action in the presence of $O$. vulgaris. However, a significantly higher number of snails (Student's $t$-test, $t=-4.243, P=0.026$ ) took evasive actions when a wrasse ( $S$. mediterraneus) was introduced into their aquarium. In this case, most snails showed a rapid movement away from the fish, while a couple of individuals reacted by withdrawing into their shells.

A large variation in the abundance of G. nivosa was recorded among different replicate samples collected from the same substratum category at a given station; this resulted in high SD values (Table 1), which suggests that the snails may have an aggregated dispersion pattern. However, Green's Index, whose value ranges from 0 for a random pattern to 1 at maximum aggregation, indicated that only slight clumping was actually present in the field, with values of 0.10 and 0.16 obtained for the near-homogeneous and homogeneous cobble/pebble beds, respectively, 0.06 for the overall habitat, and 0.01 for the $3 \times 3$ contiguous quadrats. On the other hand, Clark and Evans' $R$ statistic ranged from 1.20 to 1.63 in the experimental setups. Values of $R>1.0$ indicate a uniform distribution, but no significant departure from randomness was recorded $70 \%$ of the time. Such a random, occasionally tending to uniform, dispersion suggests that $G$. nivosa does not show gregarious behaviour.

\section{Discussion}

Population dynamics

Amongst the Mediterranean Gibbula spp., Gibbula nivosa is unique in having a very narrow distribution; apart from
Gibbula adriatica and Gibbula spratti, known only from the Adriatic Sea and Aegean Sea, respectively, all have Mediterranean-wide distributions or ones that extend along the Atlantic coasts of Portugal, Spain and France (Ghisotti and Melone 1972). In contrast, the population of G. nivosa present at Sliema Creek is the only sizeable one known to exist. As a result, temporal changes in its abundance (and hence population size) at this site need to be monitored given that a minimum viable population must be present to ensure continued survival of the species. However, abundance fluctuations are not uncommon amongst sublittoral trochids. For instance, the variation in the abundance of Jujubinus striatus living in Zostera marina beds in southern Spain recorded by Rueda et al. (2008) is comparable to that recorded for $G$. nivosa in the present study.

No information on spawning or larval development of G. nivosa is available, nor can this be deduced from knowledge of other Gibbula spp. since in this genus, both reproductive strategies whereby eggs are shed singly (hatching into free-swimming trochophore larvae) or as egg masses (from which emerge young snails that have gone through both trocophore and veliger stages within the egg mass) are known to occur (Fretter and Graham 1994). If $G$. nivosa has a similar growth rate to Gibbula umbilicalis, whose recruits $(2.5-3.0 \mathrm{~mm}$ shell width) can be observed on the shore about 2 months after spawning (Williams 1964; Kendall et al. 1987), then the presence of recruits of G. nivosa with a mean shell width of $3.82 \mathrm{~mm}$ in September 2006 suggests spawning occurred around June. Since an increase in sea temperature occurs between May and July, G. nivosa probably spawns when a given critical temperature is reached, as has been observed in Gibbula cineraria (Underwood 1972; Clare 1990).

The available data on population size structure of G. nivosa suggest that the snails grow at a rate of around $0.5 \mathrm{~mm} \mathrm{month}{ }^{-1}$, reaching an average shell width of 6.0-7.5 $\mathrm{mm}$ by the end of March. Since no shells (even empty ones) with a width $>8 \mathrm{~mm}$ were recorded from the study area, G. nivosa probably attains maximum adult size in about 1 year. Furthermore, none of the large individuals recorded in March 2008 were present in November 2008, suggesting that G. nivosa may have a short lifespan of about 1 year.

\section{Behavioural ecology}

Aspects of behavioural ecology are of direct relevance to conservation biology. For instance, knowledge of a species' activity patterns is important to establish useful monitoring strategies and census techniques (Caro 1998; Sutherland 1998). The evolutionary basis of such activity patterns is also significant since it gives insights into the selection pressures to which a species is subjected. Little (1989) discusses four such selective forces influencing 
activity patterns in intertidal molluscs: (1) desiccation and osmotic and thermal stress, (2) dislodgment by waves, (3) predation and (4) food supply. Of these, the last two factors may be equally relevant for infralittoral species such as G. nivosa.

Since algae will have maximum nutrients at the end of the photosynthetic period, it is generally profitable for grazers to feed at the end of the light period (Little 1989), which is exactly the pattern shown by $G$. nivosa. The large amount of mineral particles present in the snails' faeces, however, indicates that they did not exhibit any dietary selection but indiscriminately collected material from the surface of the cobbles, thus obtaining their energy from any organic detritus, bacteria, microalgae or epilithic biota present. Given the ubiquity of the ingested material, an area-extensive foraging strategy (sensu Schmitt 1996) probably enhances the foraging efficiency of $G$. nivosa. This accounts for the relatively fast speed at which the molluscs moved compared to congeneric species such as Gibbula umbilicaris, which averages 1-9 $\mathrm{mm} \mathrm{min}^{-1}$ while intensively grazing epiphytes at the apical region of seagrass leaves (Takada et al. 1999).

The foraging behaviour of G. nivosa can be described as a "ranging pattern" (Chelazzi et al. 1988) where movement is not oriented in a specific direction and the snails do not return to their previous shelter after a foraging bout. Homing behaviour is not required since shelter is readily available beneath the same cobbles/pebbles that serve as a feeding ground and, as noted in the present study, G. nivosa sought shelter within the cobble/pebble bed in the presence of a wrasse. Despite snails being slow-moving prey, such avoidance behaviour still reduces the risk of an attack by a fast-moving predator since it involves a response to a distant threat (Marko and Palmer 1991). Since the diurnally active wrasses (e.g. Robertson and Sheldon 1979; Siebeck and Marshall 2000) elicited a response from G. nivosa, whereas potential nocturnal predators such as starfish or octopus (Ebling et al. 1966; Meisel et al. 2003) did not, nocturnal activity by the snails may have evolved in response to diurnal predation pressure.

\section{Habitat use}

Gibbula nivosa is traditionally considered to occur in meadows of the seagrass Posidonia oceanica (Scotti and Chemello 2000), largely because it was reported from this habitat in St. Thomas Bay where the species was recorded in substantial numbers (Palazzi 1978). However, it is also known to occur under stones (Cachia 1981; Cachia et al. 1991), and Evans et al. (2010) have suggested that this may be a more important habitat for $G$. nivosa than previously thought. In fact, it is possible that individuals collected from seagrass leaves in the past were only foraging there and actually retreated to the cobble/pebble habitat (assuming this habitat was interspersed with seagrass beds) when not feeding.

Gibbula nivosa showed no aggregation in $1-\mathrm{m}^{2}$ patches of homogeneous cobble/pebble beds, nor was any gregarious behaviour noted in the experimental setups, indicating that active clustering does not occur. Thus, it appears that there is no selective pressure for $G$. nivosa to evolve aggregation behaviour. The slightly clumped distribution observed in the field at the scale of the whole habitat, therefore, is probably due to the heterogeneous nature of the cobble/pebble beds, resulting in patchiness of the preferred microhabitats.

Accumulations of cobbles and pebbles can support $G$. nivosa even in the absence of a thick homogeneous cobble/pebble bed given that the abundance of this species did not vary significantly between sites having different cobble/pebble bed thickness or of different cobble/bed homogeneity (near-homogeneous vs. homogeneous). On the other hand, a lower abundance of snails was recorded from the non-homogeneous cobble/pebble bed, which may be due to differential settlement of larvae, differential mortality rates, or to active migration to other microhabitats (Crowe and Underwood 1998; Olabarria et al. 2002). The snails were more abundant in the upper layer of the cobble/ pebble bed, where predation by fish would presumably be higher, suggesting that $G$. nivosa shows a preference for the upper strata due to factors other than predation. These may include the avoidance of anoxic conditions and waterborne silt particles that may be present in basal layers of the cobble/pebble bed and the proximity to the surface where microflora would have the highest nutritive value.

Population status and implications for conservation

Given that no live individuals of $G$. nivosa had been recorded in over 25 years in spite of intensive searches at sites where it used to occur, Schembri et al. (2007) recommended that this species should at best be considered as critically endangered under the 2001 IUCN Red List criteria (IUCN 2001). The discovery of a population at Sliema Creek and a record of live individuals from Comino by Evans et al. (2010) prove that this species is not extinct. However, the estimated extent of occurrence of this species may be $<100 \mathrm{~km}^{2}$, while its area of occupancy is $<10 \mathrm{~km}^{2}$. The population also appears to be fragmented given that the species is only known from a single site at each of two localities (Malta and Comino) that are not in close proximity, and a decline in the species' extent of occurrence has also been observed since populations at St. Thomas Bay and Santa Marija Bay may have become extinct. Thus, G. nivosa remains critically endangered with a status of CR B1ab(i) + 2ab(i) under the IUCN (2001) criteria. 
For a point-endemic species, local extinction would be equivalent to global extinction, which renders G. nivosa in dire need of proper conservation. In particular, factors that could lead to its decline need to be identified and addressed. In this respect, the situation at St. Thomas Bay provides a useful case study since G. nivosa appears to have disappeared from this locality, where it was once abundant (Schembri et al. 2007). While shell collecting may have contributed to the declines, the major cause is thought to be habitat alteration resulting from an increase in anthropogenic pressure as a result of intensive use of the bay and from coastal development (Scotti and Chemello 2000). Unfortunately, there is very little information on the state of benthic habitats at St. Thomas Bay before 1990, making it difficult to determine which factors may have led to a decline in the abundance of G. nivosa. Knowledge of the biology of G. nivosa, which was hitherto unavailable, will enable the elucidation of potentially harmful factors that conservation biologists and coastal managers need to be aware of when drawing up management plans for the species, for example, when establishing 'Special Areas of Conservation'-a legal requirement for G. nivosa given that it is listed in Annex II of the EU 'Habitats Directive'.

The sizable population of G. nivosa at Sliema Creek and the discovery of live individuals at Comino (Evans et al. 2010) are encouraging, but Sliema Creek is a very busy harbour surrounded by intense development. Declines in abundance of G. nivosa at St. Thomas Bay occurred close to a century ago (Caruana Gatto and Despott 1919). These authors noted that the species was abundant in 1916 but almost entirely absent in 1918. Furthermore, in 1974-1975, it took 12 months of searching before live individuals were finally found (Ghisotti 1976). Numerous live individuals were located in this bay only 2 years later (Palazzi 1978), but G. nivosa now appears absent from this locality (Schembri et al. 2007). Such a patchy distribution (both in space and in time) may be due to the reproductive mode of this species. Since $G$. nivosa appears to be a rapidly maturing annual species, its survival is probably dependant on the annual establishment of new populations via recruitment peaks.

Through the present study, basic data on the ecology and behaviour of the Maltese top-shell G. nivosa are available for the first time. This information will help conservation biologists and local managers to implement appropriate conservation measures for managing this critically endangered species.

Acknowledgments The present work was partly funded through a Malta Government Scholarship Scheme grant (ME 367/07/35) awarded to JE. The study conforms fully to the laws of Malta, and we thank the Malta Environment and Planning Authority for granting the necessary permits which enabled us to study the protected Maltese top-shell. We are grateful to two anonymous referees for their comments on a previous version of this paper.

\section{References}

Adams A (1851) Contributions towards a monograph of the Trochidae, a family of gastropodous Mollusca. Proc Zool Soc Lond 14:150-192

Ankel WE (1938) Erwerb und aufnahme der nahrung bei den gastropoden. Verh dtsch zool Ges Zool Anz Suppl 11:223-295

Borg JA, Micallef SA, Pirotta K, Schembri PJ (1997) Baseline marine surveys in the Maltese Islands (Central Mediterranean). In: Özhan E (ed) MEDCOAST 97, Proceedings of the third international conference, Qawra, Malta, November 11-14, 1997

Borg JA, Attril MJ, Rowden AA, Schembri PJ, Jones MB (2002) A quantitative technique for sampling motile macroinvertebrates in beds of the seagrass Posidonia oceanica (L.) Delile. Sci Mar 66:53-58

Boudouresque CF (2004) Marine biodiversity in the Mediterranean: status of species, populations and communities. Sci Rep Port Cros Natl Park 20:97-146

Cachia C (1981) Notes on some uncommon species of molluscs from the Maltese Islands. Boll Malacol 17:291-294

Cachia C, Mifsud C, Sammut PM (1991) The marine shelled Mollusca of the Maltese Islands (Part One: Archaeogastropoda). Grima Printing and Publishing Industries, Msida

Caro T (1998) The significance of behavioural ecology to conservation biology. In: Caro $\mathrm{T}$ (ed) Behavioural ecology and conservation biology. Oxford University Press, New York, pp 3-26

Caruana Gatto A, Despott G (1919) Materiali per una malacofauna marina delle Isole Maltesi. Arch Melit 3:431-446

Chatfield C (2004) The analysis of time series: an introduction, 6th edn. CRC Press LLC, Florida

Chelazzi G, Focardi S, Deneubourg J (1988) Analysis of movement patterns and orientation mechanisms in intertidal chitons and gastropods. In: Chelazzi G, Vannini M (eds) Behavioural adaptation to intertidal life. Plenum Publishing Corporation, New York, pp 173-184

Clare AS (1990) Laboratory-induced spawning of the gastropod Gibbula cineraria as an indicator of field spawning. Mar Ecol Prog Ser 63:303-304

Clark PJ, Evans FC (1954) Distance to nearest neighbor as a measure of spatial relationships in populations. Ecology 35:445-453

Crowe TP, Underwood AJ (1998) Testing behavioural "preference" for suitable microhabitat. J Exp Mar Biol Ecol 225:1-11

Despott G (1919) The Mollusca of Marsascirocco Harbour, Malta. Proc Zool Soc Lond 13:168-183

Ebling FJ, Hawkins AD, Kitching JA, Muntz L, Pratt VM (1966) The ecology of Lough Ine. XVI. Predation and diurnal migration in the Paracentrotus community. J Anim Ecol 35:559-566

Evans J, Borg JA, Schembri PJ (2010) Rediscovery of live Gibbula nivosa (Gastropoda: Trochidae). Rapp Comm Int Mer Medit 39:507

Fretter V, Graham A (1994) British prosobranch molluscs: their functional anatomy and ecology, 2nd edn. The Ray Society, London

Ghisotti F (1976) Considerazioni su Gibbula nivosa A. Adams, 1851. Conchiglie 12:79-88

Ghisotti F, Melone G (1972) Catalogo illustrato delle conchiglie marine del Mediterraneo. Conchiglie Suppl 4:79-144

Giannuzzi-Savelli R, Pusateri F, Palmeri A, Ebreo C (1997) Atlante delle conchiglie marine del Mediterraneo, volume 1: Archaeogastropoda. La Conchiglia, Rome

Green RH (1966) Measurement of non-randomness in spatial distributions. Res Pop Eco 8:1-7

IUCN (2001) IUCN Red List categories and criteria: version 3.1. IUCN species survival commission. Gland, Switzerland 
Kendall MA, Williamson P, Garwood PR (1987) Annual variation in recruitment and population structure of Monodonta lineata and Gibbula umbilicalis populations at Aberaeron, Mid-Wales. Est Coast Shelf Sci 24:499-511

Kobelt W (1888) Prodromus faunae molluscorum testaceorum maria europaea inhabitantium. Von Bauer e Raspe, Nürnberg

Little C (1989) Factors governing patterns of foraging activity in littoral marine herbivorous molluscs. J Mollus Stud 55:273-284

Mallia A, Briguglio M, Ellul AE, Formosa S (2002) Physical background, demography, tourism, mineral resources and landuse. In: Axiak V, Gauci V, Mallia A, Mallia E, Schembri PJ, Vella AJ, Vella L (eds) State of the environment report for Malta, 2002. Ministry for Home Affairs and the Environment, Malta, pp 39-161

Marko PB, Palmer AR (1991) Responses of a rocky shore gastropod to the effluents of predatory and non-predatory crabs: avoidance and attraction. Biol Bull 181:363-370

Meisel DV, Byrne RA, Kuba M, Griebel U, Mather JA (2003) Circadian rhythms in Octopus vulgaris. In: Warnke K, Keupp H, Boletzky Sv (eds) Coleoid cephalopods through time. Berl Palaobiolgische Abh 3:171-177

Olabarria C, Underwood AJ, Chapman MG (2002) Appropriate experimental design to evaluate preferences for microhabitat: an example of preferences by species of microgastropods. Oecologia 132:159-166

Palazzi S (1978) Osservazioni sull'habitat di Gibbula nivosa A. Adams, 1851. Conchiglie 14:177-180

Robertson DR, Sheldon JM (1979) Competitive interactions and the availability of sleeping sites for a diurnal coral reef fish. J Exp Mar Biol Ecol 40:285-298

Rueda JL, Marina P, Salas C, Urra J (2008) Jujubinus striatus (Linnaeus, 1758) (Gastropoda: Trochidae) from a deep Zostera marina bed in southern Spain (Alboran sea): aspects of ecology and biology. J Mollus Stud 74:345-354

Schembri PJ (1985) The Maltese top-shell. Civilization 19:518-519

Schembri PJ, Borg JA, Deidun A, Knittweis L, Mellado Lopez T (2007) Is the endemic Maltese topshell Gibbula nivosa extinct? Rapp Comm Int Mer Médit 38:592

Schmitt RJ (1996) Exploitation competition in mobile grazers: tradeoffs in use of a limited resource. Ecology 77:408-425

Scotti G, Chemello R (2000) I molluschi marini mediterranei degni di protezione: stato di conoscenza e forme di tutela. Boll Malacol 36:61-70

Siebeck UE, Marshall NJ (2000) Transmission of ocular media in labrid fishes. Philos Trans R Soc B 355:1257-1261

Sutherland WJ (1998) The importance of behavioural studies in conservation biology. Anim Behav 56:801-809

Takada Y, Russo GF, Mazzella L (1999) Activity patterns and habitat preferences of two herbivorous gastropods (Gibbula umbilicaris and Jujubinus exasperatus) on leaves of the Mediterranean seagrass Posidonia oceanica. Benthos Res 54:71-80

Thake MA, Schembri PJ (1989) Mollusca. In: Schembri PJ, Sultana J (eds) Red data book for the Maltese Islands. Department of Information, Valletta, pp 79-89

Underwood AJ (1972) Spawning, larval development and settlement behaviour of Gibbula cineraria (Gastropoda: Prosobranchia) with a reappraisal of torsion in gastropods. Mar Biol 17:341-349

Williams EE (1964) The growth and distribution of Gibbula umbilicalis (Da Costa) on a rocky shore in Wales. J Anim Ecol 33:433-442

Zar JH (1996) Biostatistical analysis, 3rd edn. Prentice-Hall Inc., New Jersey 